\title{
CLASSIFICAÇÃO ETNOBIOLÓGICA DE CRUSTÁCEOS (DECAPODA: BRACHYURA) POR PESCADORES ARTESANAIS DO MUNICÍPIO DE CONDE, LITORAL NORTE DO ESTADO DA BAHIA, BRASIL
}

\author{
ETHNOBIOLOGICAL CLASSIFICATION OF CRABS (DECAPODA: BRACHYURA) ACCORDING TO ARTISANAL \\ FISHERMEN FROM THE MUNICIPALITY OF CONDE, NORTH COAST OF BAHIA STATE, BRAZIL
}

\author{
Henrique Fernandes MAGALHÃES ${ }^{1}$, Eraldo Medeiros COSTA NETO ${ }^{1 *}$, Alexandre SCHIAVETTI ${ }^{2}$
}

\section{RESUMO}

Os sistemas de classificação etnobiológicos frequentemente difundem-se pela oralidade. Sua interpretação leva a compreender como as sociedades humanas nomeiam e ordenam os elementos de seu ambiente. O presente estudo teve por objetivo registrar a classificação etnobiológica de crustáceos braquiúros de importância econômica no município de Conde, Litoral Norte da Bahia, Nordeste do Brasil. O trabalho de campo foi realizado no período de setembro de 2007 a dezembro de 2009, mediante o uso de técnicas etnográficas usuais, como entrevistas abertas e semiestruturadas, bem como observações comportamentais. Foram entrevistados, individual ou coletivamente em variados contextos, pescadores artesanais $(n=57)$, de ambos os gêneros, com idades entre 10 e 78 anos, acerca dos nomes populares e dos principais critérios adotados na identificação etnotaxonômica dos braquiúros de importância econômica na região. Foram visitadas sete comunidades pesqueiras: Siribinha, Sítio do Conde, Poças, Ilha das Ostras, Cobó, Buri e Sempre Viva. Os dados referentes à etnotaxonomia dos crustáceos foram analisados segundo os Princípios de Classificação Etnobiológica de Brent Berlin. Os resultados mostram que braquiúros de importância econômica são classificados na Forma de Vida Marisco. Seis táxons específicos de siris (Portunidae) foram registrados e nomeados com base em critérios ecológicos e morfológicos. Alguns dos nomes comuns referentes à Ucides cordatus e Cardisoma guanhumi obedecem a esses mesmos critérios. Com base nos resultados, percebe-se que o sistema de classificação etnobiológico adotado em Conde reflete os saberes relacionados a aspectos biológicos e ecológicos dos braquiúros.

PALAVRAS-CHAVE: caranguejos, etnotaxonomia, pesca artesanal

\footnotetext{
${ }^{1}$ Universidade Estadual de Feira de Santana, Departamento de Ciências Biológicas, Feira de Santana, Bahia, Brasil CEP: 440.36900

${ }^{2}$ Universidade Estadual de Santa Cruz, Departamento de Ciências Agrárias e Ambientais, Ilhéus, Bahia, Brasil, CEP: 456.62900

*eraldomcosta@gmail.com
} 


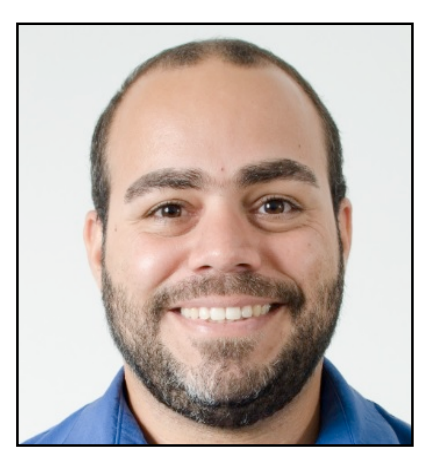

Henrique possui graduação em Ciência Biológicas pela Universidade Estadual de Feira de Santana (UEFS); especialização em Gestão Ambiental e MBA em Perícia, Auditoria e Análise Ambiental (em andamento), ambos pela Universidade Cândido Mendes; mestrado em Zoologia, pela Universidade Estadual de Santa Cruz (IJESC).

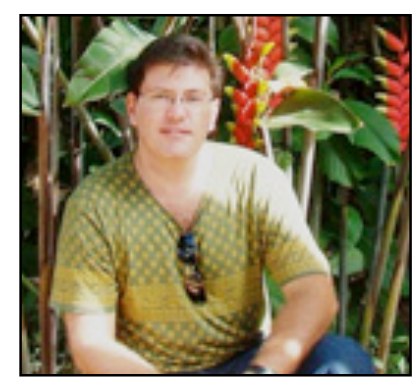

Eraldo Neto possui graduação em Licenciatura em Biologia pela Universidade Federal de Alagoas (1994), mestrado em Desenvolvimento e Meio Ambiente pela Universidade Federal de Alagoas (1998) e doutorado em Ecologia e Recursos Naturais pela Universidade Federal de São Carlos (2003). Pós-doutorado na Universidade Nacional Autônoma do México, Instituto de Biologia (2005) Professor Pleno da Universidade Estadual de Feira de Santana

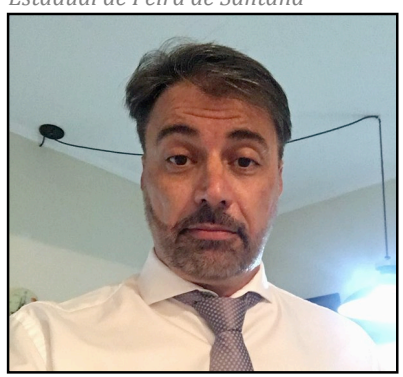

Alexandre possui graduação em Ecologia pela Universidade Estadual Paulista Júlio de Mesquita Filho (1991), mestrado em Ciências da Engenharia Ambiental pela Universidade de São Paulo (1997), doutorado em Ecologia e Recursos Naturais pela Universidade Federal de São Carlos (2002) e pósdoutorado no Centro Nacional Patagônico (CENPAT - Puerto Madryn). Professor Pleno da Universidade Estadual de Santa Cruz e pesquisador associado aos Projetos Coral Vivo e Golfinho Rotador.

\section{ETHNOBIOLOGICALCLASSIFICATION OF CRABS (DECAPODA: BRACHYURA) ACCORDING TO ARTISANAL FISHERMEN FROM THE MUNICIPALITY OF CONDE, NORTH COAST OF BAHIA STATE, BRAZIL}

\section{ABSTRACT}

Ethnobiological classification systems often spread through oral traditions. Their interpretation leads to understanding how human societies nominate and categorize the elements in their environments. The present study aimed to record the ethnobiological classification of those brachyuran crustaceans of economic importance in the municipality of Conde, located at the North region of Bahia State, northeast Brazil. Fieldwork was done from September 2007 to December 2009, and the data were recorded by means of usual ethnographic techniques such as open and semi-structured interviews and behavioral observations. A sample of 57 artisanal fishermen of both genders, aged 10 to 78 years, were interviewed, individually or collectively in varying contexts, aboutthe popular names and criteria adopted for nominating brachyurans of economic importance in the region. Seven fishing communities were visited: Siribinha, Sítio do Conde, Poças, Ilha das Ostras, Cobó, Buri and Sempre Viva. The data regarding crabs' ethnotaxonomy were analyzed according to Brent Berlin's Principles of Ethnobiological Classification. The results show that these brachyurans are ranked in the Life Form "Marisco". Six taxa of crabs (Portunidae) were recorded based on ecological and morphological criteria. Some of the common names used to refer to Ucides cordatus and Cardisoma guanhumi obey to these same criteria. Based on the results, it can be seen that the ethnobiological classification system which is adopted in Conde reflects local knowledge related to biological and ecological aspects of brachyurans.

KEYWORDS: artisanal fishing, crabs, ethnotaxonomy

\section{INTRODUÇÃO}

Os sistemas de classificação etnobiológicos estão intrinsecamente relacionados ao modo como as sociedades humanas percebem e interagem com o mundo natural e, por conseguinte, com a fauna e flora presentes no ambiente onde vivem. Segundo Mourão e Nordi (2002), a taxonomia da natureza, elaborada por tais comunidades, frequentemente difunde-se oralmente e sua interpretação, por meio de pesquisas etnobiológicas, pode conduzir à lógica dos pensamentos e atitudes dos povos. Em suma, esta ciência investiga como o mundo é percebido, identificado e compreendido pelas diversas culturas humanas, o que pode 
ser entendido como um reflexo de como as sociedades nomeiam e ordenam os elementos de seu ambiente em sistemas de classificação (TURBAY, 2002).

Uma vez que cada língua determina o próprio recorte de uma sociedade, a compreensão das categorias semânticas permite o acesso não somente ao conhecimento de uma sociedade sobre o meio natural no qual ela vive, mas igualmente à sua visão de mundo (ROUÉ, 1997). De acordo com Harris (1976), cada sociedade confere um significado ao seu mundo natural e à diversidade de organismos (reais e/ou mitológicos) presentes nos ecossistemas, baseado em aspectos cognitivos e linguísticos. Os padrões de expressão linguística de uma dada cultura indicam qualquer regularidade classificatória, em que categorias são consideradas construções linguísticas que capacitam uma cultura a dar ordem a seu universo, organizando suas percepções coletivas e as relações dos seres com os fenômenos (GREENE, 1995). Sendo assim, todos os grupos humanos organizam seu mundo perceptual e respondem a ele em sistemas de categorizações compartilhados (HYNOBRAN, 1984).

Os crustáceos são animais bem característicos de regiões de manguezais e desempenham um papel na dinâmica do ecossistema, não só pela função na cadeia alimentar, como também porque alguns deles, os braquiúros, atuam no processamento da serapilheira, no fluxo energético, na bioturbação do sedimento e na ciclagem do carbono e da matéria orgânica (GUEST et al., 2006; SILVA, 2014). Constituem um grupo diverso e fazem parte de uma das maiores biomassas no ecossistema marinho (RUPPERT et al., 2005).

Dentre as interações que a espécie humana mantém com os crustáceos braquiúros, podese visualizar seu uso para fins diversos: como artesanato (ALVES et al., 2006; SILVA et al., 2007), fonte de renda e na alimentação (REITERMAJER, 1996; NOMURA, 2001; SOUTO, 2004), na medicina popular (LAGESFILHO, 1934; MAGALHÃES, 1966; COSTA-NETO e GORDIANO-LIMA, 2000) e em atividades lúdicas (CASCUDO, 1972). As interações que se estabelecem entre os seres humanos e os crustáceos constituem o campo de estudo da etnocarcinologia a qual pode ser definida, parafraseando-se Posey (1986), como a parte da etnozoologia que investiga o conhecimento, a classificação e os modos de utilização dos crustáceos pelas sociedades humanas.

Crustáceos braquiúros são recursos pesqueiros com elevado valor socioeconômico para as comunidades que habitam zonas estuarinas, sendo que muitas dessas populações sobrevivem exclusivamente da exploração desses recursos (SCHAEFFER-NOVELLI, 1995; JANKOWSKY et al., 2006; NASCIMENTO et al., 2008; MAGALHÃES et al., 2012). Partindo-se do princípio de que comunidades humanas nomeiam e classificam os organismos vivos que integram seu mundo natural de acordo com suas observações e aprendizados, resultado de seu modus vivendi, este artigo apresenta a classificação etnobiológica dos crustáceos braquiúros de importância econômica na região de Conde, Litoral Norte do Estado da Bahia, nordeste do Brasil, utilizada por pescadores artesanais, abordando tanto os sistemas de classificação usados pelos mesmos, como a construção cultural de domínios etnotaxonômicos, relacionando-a ao conhecimento etnoecológico destes pescadores. 


\section{METODOLOGIA}

Área de estudo

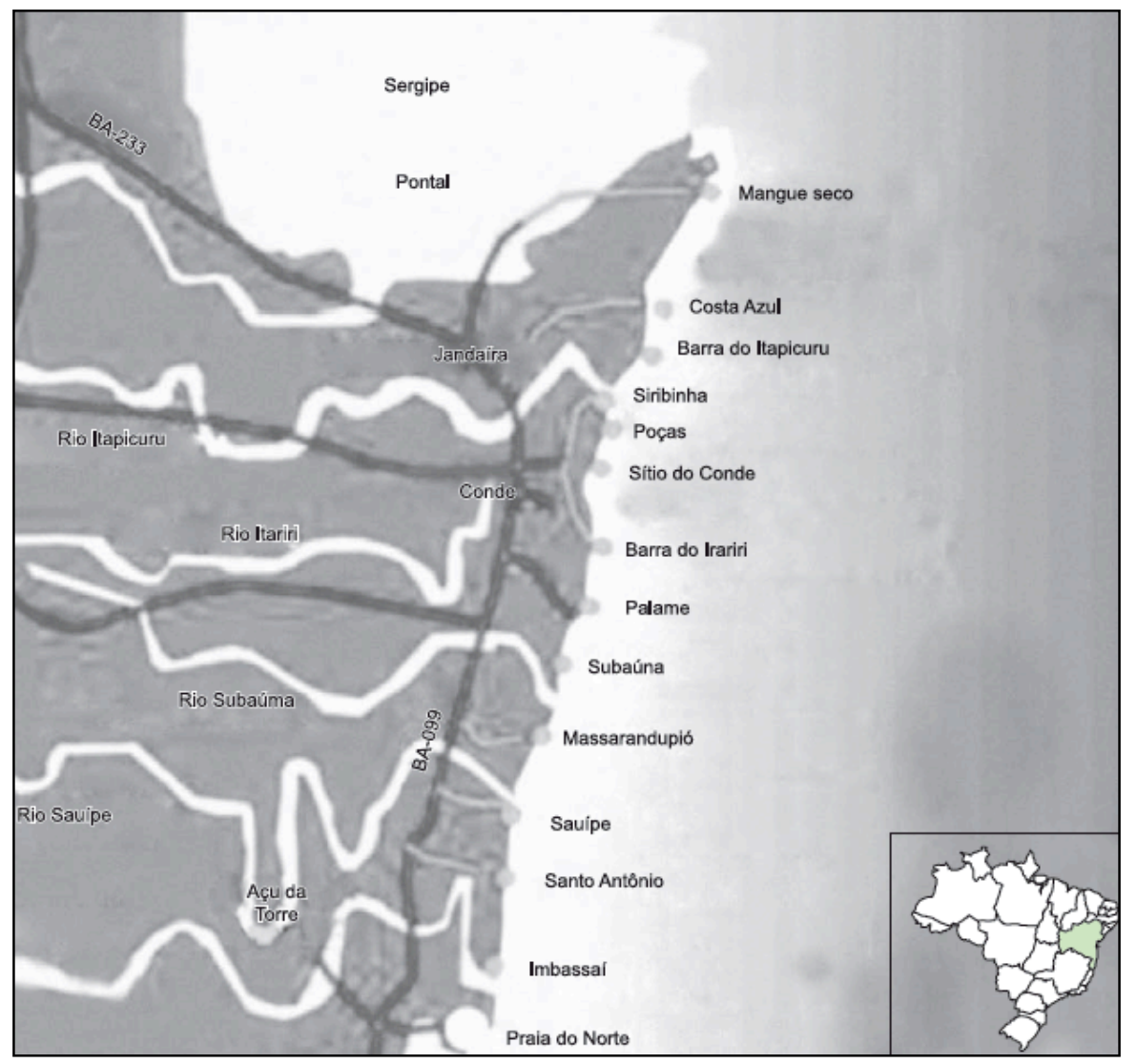

Figura 1: Localização do município de Conde e de algumas das principais comunidades pesqueiras estudadas. Adaptado de CostaNeto (2000)

se constitui em um eco-complexo, o qual Blandin e Lamotte (1988) definiram como um conjunto de ecossistemas interligados (naturais ou modificados) que têm uma história ecológica e antrópica comum e que apresenta novas propriedades emergentes, o que confere à região uma vasta diversidade biológica.

Segundo Costa-Neto (2001), a região, distribuída em aproximadamente $40 \mathrm{~km}$ de praias, dunas, brejos, rios, lagoas e estuários, possui duas desembocaduras: a Barra do Rio Itapicuru, ao norte, e a Barra do Rio Itariri, ao sul. Vários povoados formam o município, como Altamira, Cobó, Cangurito, Barra do Itariri, Sítio do Conde, Poças e Siribinha, entre outros. Devido à sua importância no cenário paisagístico-ecológico e social, a região foi transformada em uma Área de Proteção Ambiental (APA) em março de 1992, com posterior elaboração de seu Plano de Manejo em 1995 (COSTA-NETO, 2001).

\section{Metodologia}

O trabalho de campo, em sua etapa inicial, foi desenvolvido no período entre setembro de 2007 a dezembro de 2009, realizando-se visitas mensais a sete comunidades pesqueiras do município do Conde: Siribinha, Poças, Sítio do Conde, Ilha das Ostras, Cobó, Buri e Sempre Viva. Os 
dados foram obtidos por meio de entrevistas abertas e semiestruturadas. Uma vez selecionados os meses de visitação, procurou-se contemplar as duas estações do ano reconhecidas pelas comunidades pesqueiras: "verão" (setembro-março) e "inverno" (abril-agosto), correlacionando os dados obtidos durante as mesmas.

As entrevistas foram realizadas seguindo-se preceitos etnocientíficos com enfoque emicista-eticista balanceado (STURTEVANT, 1964). Foram entrevistados 57 indivíduos, sendo 48 homens $(84,2 \%)$ e 9 mulheres $(15,8 \%)$, cujas idades variaram entre 10 e 78 anos, distribuídos heterogeneamente entre as sete comunidades inventariadas. Trata-se de pescadores e pescadoras que sobrevivem da coleta de aratus, caranguejos e siris, tendo sido contatados segundo a técnica bola-de-neve (GOODMAN, 1961), segundo a qual um especialista local indica outro e assim sucessivamente. As entrevistas foram registradas em gravadores digitais e posteriormente transcritas para análise dos dados. Os moradores entrevistados foram questionados acerca dos nomes populares e dos critérios que adotam para nomear os braquiúros de importância econômica da região. O estudo fora aprovado pelo Comitê de Ética em pesquisa com seres humanos da Universidade Estadual de Feira de Santana. Os indivíduos tiveram acesso ao Termo de Consentimento Livre e Esclarecido, concordando em participar do estudo.

Todo material etnográfico (gravações, transcrições, caderno de campo e fotografias) encontra-se guardado no Laboratório de Etnobiologia e Etnoecologia da Universidade Estadual de Feira de Santana, aos cuidados do curador da seção Etnozoologia do Museu de Zoologia da UEFS.

Os dados etnográficos foram analisados qualitativamente, considerando-se todas as informações citadas pelos entrevistados. Os controles foram feitos por meio de testes de verificação de consistência e de validade das respostas, recorrendo-se a entrevistas repetidas em situações sincrônicas e diacrônicas: as primeiras ocorrem quando uma mesma pergunta é direcionada a indivíduos diferentes em tempos bastante próximos; enquanto nas segundas, uma pergunta é repetida ao mesmo indivíduo em tempos bem distintos (WERNER, 1969).

Excursões ao manguezal da região de Conde foram realizadas com o auxílio de guias locais, visando à coleta de espécimes pelos próprios sujeitos. A técnica empregada nessas saídas de campo foi a de turnê (SPRADLEY e MCCURDY, 1972), quando o pesquisador seguia pelo caminho determinado pelo participante da pesquisa, à medida que este relatava acerca do que observava. Tais coletas possibilitaram a realização posterior de testes projetivos, os quais consistiram na apresentação tanto das fotografias quanto dos próprios espécimes aos participantes da pesquisa para que falassem sobre a taxonomia popular adotada na região.

Os espécimes coletados foram selecionados e identificados até o menor nível taxonômico possível pelo Dr. César Carqueija (Faculdade de Tecnologia e Ciências com sede em Salvador), e posteriormente depositados no Museu de Zoologia da FTC/Salvador. Duplicatas foram depositadas na coleção de invertebrados do Museu de Zoologia da Universidade Estadual de Feira de Santana (MZUEFS), e também na coleção zoológica da Universidade Estadual de Santa Cruz. Os espécimes que não foram coletados foram identificados com base em uma pista taxonômica de acordo com informações obtidas pelo referido especialista. 


\section{RESULTADOS E DISCUSSÃO}

Os crustáceos braquiúros de importância econômica em Conde são taxonomicamente incluídos no domínio etnossemântico "marisco", juntamente com outros recursos pesqueiros, como lagostas (Palinura), camarões (Penaeidea), moluscos (p. ex, Anomalocardia brasiliana Gmelin, 1791), além de um peixe da família Gobiidae conhecido localmente como moreia (Bathygobius soporator Valenciennes, 1837). Esses "mariscos", por sua vez, são classificados de acordo com o hábitat onde são coletados: "mariscos do mangue"(p. ex., caranguejo-uçá, siri-do-mangue, aratu, moreia) e "mariscos do rio" (p. ex., siri-do-rio, siri-ponta-coroa).

"Tudo o que dá aqui a gente chama de marisco. Aqui tem mais, que nós conhece, o marisco do mangue. Tem também o marisco do rio, que é mais diferente. É outra pescaria diferente da pescaria do mangue [...]. Tem o aratu, a moreia e tem o siri. Do mangue, né? Mas tem o siri-do-rio, que é do rio mesmo. E tem o siri-do-mangue que vem do mangue mesmo" (Seu C., 65 anos).

O caso da moreia é interessante, pois apresenta duas etnocategorias semânticas: peixe e marisco: "A moreia é peixe, mas é marisco também" (Dona A., 54 anos). Isso se deve, provavelmente, ao fato desse animal ser encontrado facilmente no mangue, juntamente com outros recursos pesqueiros identificados como mariscos ("mariscos do mangue"), sendo um dos recursos pesqueiros de importância econômica, constituindo, assim, uma classificação por "associação".

De acordo com os princípios da classificação etnobiológica propostos por Berlin (1992), a etnocategoria Marisco corresponderia ao nível etnotaxonômico Forma de Vida. No sistema de classificação etnobiológico dos pescadores e pescadoras artesanais de Conde, ocorrem quatro táxons genéricos, que são Peixe, Caranguejo, Aratu e Siri. Apenas o genérico Aratu constitui um táxon monotípico e polissêmico, isto é, não apresenta táxons específicos ("Aratu só tem de um tipo mesmo",Seu E. V., 75 anos), funcionando tanto como genérico quanto específico ao mesmo tempo (Tabela 1; Figura 2). Os demais se caracterizam como genéricos politípicos. Ressalta-se que os pescadores e pescadores de Conde se referem aos animais que coletam para fins culturais diversos de acordo com os tipos de organismos que se associam com cada táxon genérico (ver Tabela 1).

Alves e Souza (2000) registraram que o termo "marisco", entre as mulheres pescadoras do Canal de Santa Cruz (Estado de Pernambuco), é utilizado apenas para designar moluscos bivalves, ou ainda apenas a espécie Anomalocardia brasiliana (Gmelin, 1971). Nesse mesmo estudo, caranguejos, gaiamuns e siris, juntamente com bivalves ("mariscos"), lagostas e camarões, são classificados pelas marisqueiras como "crustáceos". Souto (2004), em estudo desenvolvido na comunidade pesqueira de Acupe (Santo Amaro, Bahia), registrou as categorias "marisco" e "peixe", que foram definidas e diferenciadas por pescadores e marisqueiras segundo critérios morfológicos ("[...] marisco tem casca [...] o peixe tem escama ou couro"), ecológicos ("O marisco se panha no mangue [...] o peixe é pescado no mar") e de estratégia de captura ("[...] o marisco se panha com as mão, com o gancho [...] o peixe se panha de rede"). 
Tabela 1. Classificação etnobiológica dos crustáceos braquiúros de importância econômica, segundo pescadores artesanais de Conde, e sua correspondência lineana

\begin{tabular}{|c|c|c|c|}
\hline \multicolumn{3}{|c|}{ Níveis Hierárquicos } & \multirow{2}{*}{$\begin{array}{l}\text { Correspondência lineana } \\
\text { (Pista taxonômica) }\end{array}$} \\
\hline Forma de vida & Genéricos & Específicos & \\
\hline \multirow{17}{*}{ Marisco } & Peixe & Moreia & Bathygobius soporator Valenciennes, 1837 \\
\hline & & Caranguejo-uçá & \\
\hline & & Caranguejo-uçau & Ucides cordatus (Linnaeus, 1763) \\
\hline & & Caranguejo-da-lama & \\
\hline & & Caranguejo-gaiamum & \\
\hline & Caranguejo & Caranguejo-da-terra & \\
\hline & & Caranguejo-de-brejo & Cardisoma guanhumi Latreille, 1825 \\
\hline & & Caranguejo-do-mato & \\
\hline & & Caranguejo-azul & \\
\hline & Aratu & & Goniopsis cruentata (Latreille, 1803) \\
\hline & & Siri-de-pedra* & Arenaeus sp. \\
\hline & & & Callinectes exasperatus (Gerstaeker, 1856) \\
\hline & & Sırı-do-mangue & Callinectes danae Smith, 1869 \\
\hline & Siri & Siri-do-rio & Callinectes danae Smith, 1869 \\
\hline & & Siri-ponta-coroa* & Callinectes larvatus Ordway, 1863 \\
\hline & & & Callinectes danae Smith, 1869 \\
\hline & & $\begin{array}{l}\text { Siri-nema } \\
\text { Siri-sara }\end{array}$ & Callinectes bocourti A. Milne-Edwards, 1879 \\
\hline
\end{tabular}

*Animal não coletado. Identificação baseada em literatura (REITERMAJER, 1996; SOUTO, 2004).

Embora autores, como Ruppert et al. (2005), classifiquem os animais que compõem a infraordem Brachyura como "caranguejos verdadeiros", os pescadores artesanais de Conde diferenciam o etnotáxon Caranguejo, que abrange Ucides cordatus e Cardisoma guanhumi, dos demais táxons genéricos Siri e Aratu:"Caranguejo daqui conhecido só sei mesmo do uçau e do gaiamum. Daqui de nossa área são só esses" (Seu F., 41 anos); "Aratu já é aratu, não é caranguejo" (Seu E., 75 anos).

Dentro da etnocategoria Caranguejo, por sua vez, critérios morfológicos e ecológicos (hábitat) são utilizados na diferenciação das duas espécies de importância econômica registradas:

"Não são porque o uçau tá no mangue, na lama, e os gaiamum só tá nas beirada do rio, nas beirada dos brejo" (Seu V., 59 anos)

"Rapaz, eu acho que não é não [...] eles não têm muita aparência um com o outro não" (I., 21 anos)

No táxon genérico Siri (Fig. 3), os pescadores citaram cinco específicos: siri-do-mangue (Callinectes exasperatus/ Callinectes danae); siri-do-rio (Callinectes danae); siri-nema ou siri-sara (Callinectes bocourti); siri-de-pedra (Arenaeus sp.); e siri-ponta-coroa (Callinectes larvatus/ Callinectes danae). Este último não apresenta importância econômica local devido ao seu 
tamanho diminuto ("Tem o siri ponta-coroa, que é um que não tem comércio nenhum. Ninguém usa pra nada [...]", Seu F., 41 anos). A espécie Callinectes danae correspondeu a dois dos etnotáxons coletados, siri-do-rio e siri-do-mangue, apontando uma sinonímia, ou seja, uma mesma espécie lineana que corresponde a duas ou mais etnoespécies. Dois diferentes critérios foram utilizados na construção cultural do sistema de classificação etnobiológica local: ecológico, notadamente relacionados ao tipo de hábitat (siri-do-mangue, siri-do-rio, siri-de-pedra); e morfológico (siri-ponta-coroa, siri-sara):

"Tem o siri-do-mangue e o siri-de-pedra, que só dá em pedra. Cada um é de uma espécie, de um jeito diferente" (I., 21 anos)

"Tem o que a gente chama do mangue, tem o do rio. Tem um que a gente chama siri-sara, siri-nema. Tem um também que a gente chama ponta-coroa, que é um que o bico dele é grande. O casco dele é muito comprido" (Seu F., 40 anos)

"O siri-sara tem esse nome porque ele tem o casco com umas pintinhas, parecendo ferrugem. Ele é meio 'sararazinho' mesmo. Por isso tem esse nome. Já o 'nema', é a mesma coisa do 'sara' (Seu A., 72 anos)

"Eu acho, na minha opinião, que o uçau tem esse nome por causa do lugar que ele vive, que a água é salgada. Por isso esse nome: 'u-sal' [...]" (Seu N., 44 anos)

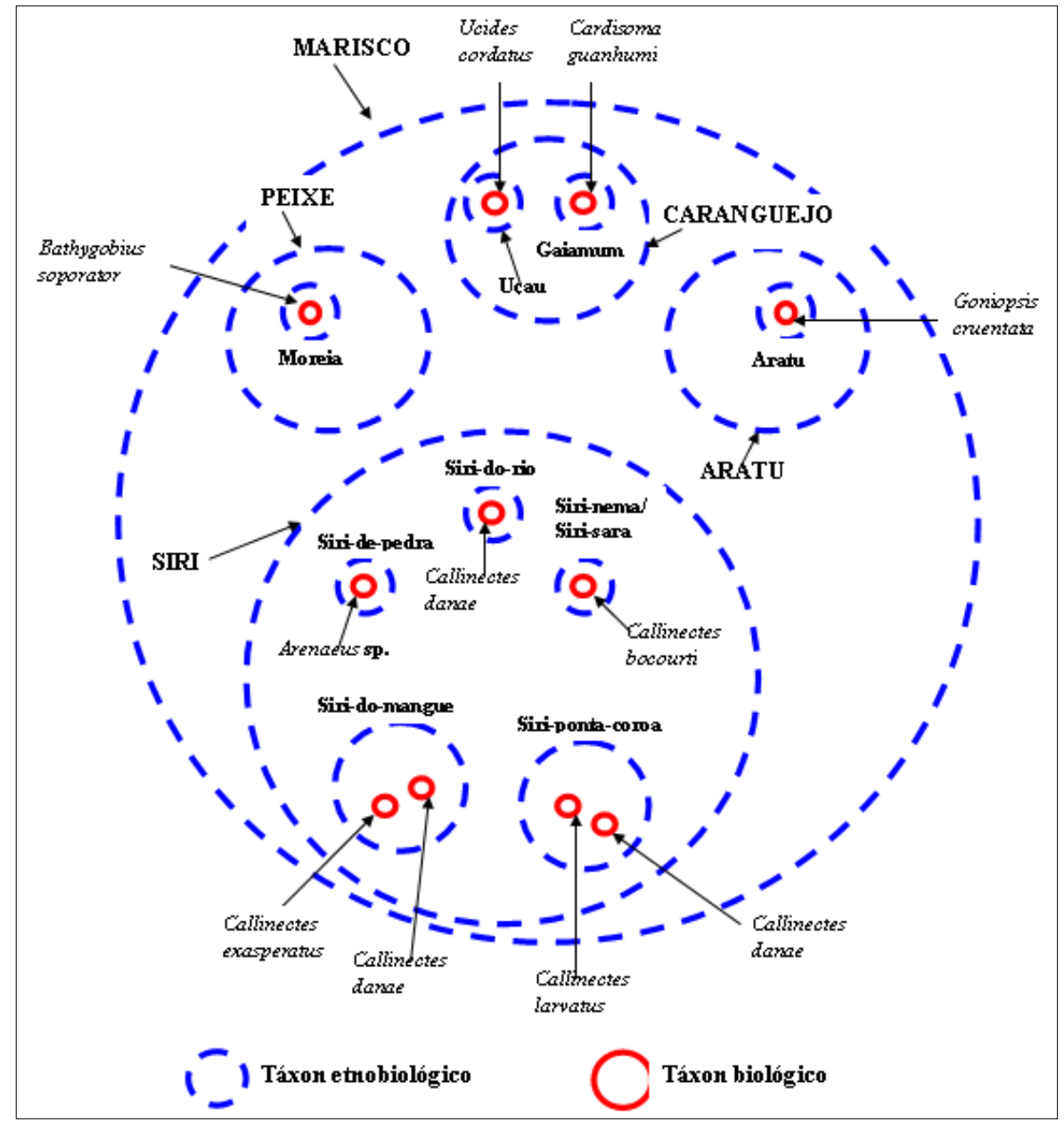

Figura 2: Diagrama de Venn, representando o sistema de classificação etnobiológica adotado pelos pescadores artesanais de Conde para crustáceos braquiúros de importância econômica local 


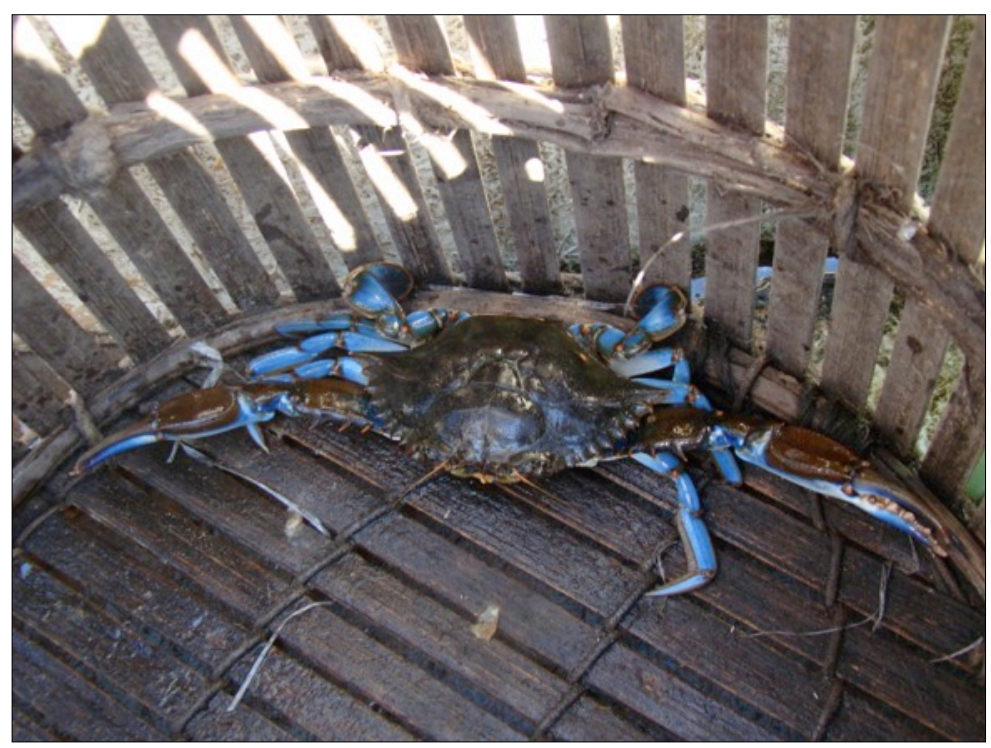

Figura 3: Callinectes exasperatus. Foto: Henrique F. de Magalhães
Dos 15 nomes comuns registrados em Conde para os crustáceos braquiúros de importância econômica local, 13 são binomiais e dois são monomiais. A estrutura de nomes específicos, segundo os princípios da classificação etnobiológica de Berlin (1992), é regularmente binomial, com 0 genérico modificado por um adjetivo que usualmente designa algum caráter morfológico ou ecológico

óbvio. Os nomes específicos monomiais, quando ocorrem, são polissêmicos com seus genéricos

superordenados mais bem conhecidos ou com aqueles mais largamente distribuídos (BERLIN, 1992). De acordo com este autor, o critério predominante na formação dos nomes comuns é o hábitat (padrão ecológico), seguido pela coloração (padrão morfológico), conforme evidenciado na Tabela 2.

No que se refere à etimologia dos nomes comuns dados aos crustáceos braquiúros de valor socioeconômico, necessita-se investigar, à luz da abordagem ecolinguística (COUTO, 2007), o significado e origem local dos nomes comuns. Por exemplo, enquanto nomes como caranguejodo-mangue e siri-de-ponta aludem a aspetos cológicos e morfológicos, respectivamente, outros etnonomes necessitam de maior investigação, a exemplo de siri-nema e siri-sara.

Reitermajer (1996), em seu estudo acerca do extrativismo em manguezal no Norte da Bahia, documentou os nomes comuns siri-de-mangue (Callinectes exasperatus) e siri-nema ( $C$. danae), além do siri-de-ponta (C. bocourti); Costa-Neto e Gordiano-Lima (2000) registraram os nomes siri-nema ( $C$. exasperatus) e siri-coceira ( $C$. marginatus) entre pescadores artesanais das comunidades pesqueiras de Siribinha e Poças (Conde-BA); Souto e Marques (2006) evidenciaram, na comunidade pesqueira de Acupe (Santo Amaro-BA), a existência de critérios ecológicos com base no hábitat (siri-de-coroa, siri-de-vaza, siri-de-mangue), morfológicos (siri-aranha, siri-boceta), comportamentais (siri-dorminhoco) e de "origem" (siri-paraguai), na construção da nomenclatura para os siris; Ferreira et al. (2007) identificaram, entre pescadores do Estuário do Rio Mamanguape (Estado da Paraíba), quatro níveis hierárquicos dentro da classificação berliniana Reino, Forma de Vida, Genérico e Específicos - sendo estes identificados por meio de caracteres morfológicos (siri-açú, siri-pontinha, siri-pintado), pelo cheiro (siri-cagão) e pelo gosto (siripimenta); Silva e Nishida (2008), em estudo acerca da etnoclassificação de siris entre os pescadores da região estuarina do Rio Vaza-Barris (Estado de Sergipe), identificaram dez "tipos" de siris, que foram classificados também segundo critérios morfológicos e ecológicos. 
A designação "caranguejo-delama" é utilizada pelos pescadores artesanais de Conde para Ucides cordatus e está relacionada ao tipo de habitat no qual o animal é encontrado, além dos nomes caranguejo-uçau ou, apenas, uçau. $\mathrm{Na}$ comunidade pesqueira de Acupe (Santo Amaro-BA), esta espécie é denominada simplesmente caranguejo (SOUTO, 2004); os índios Tupinambás que habitavam a região do Recôncavo baiano o reconheciam simplesmente por "uçás", conforme registrado por Gabriel Soares de Souza em 1587 (apud SOUZA, 2000).

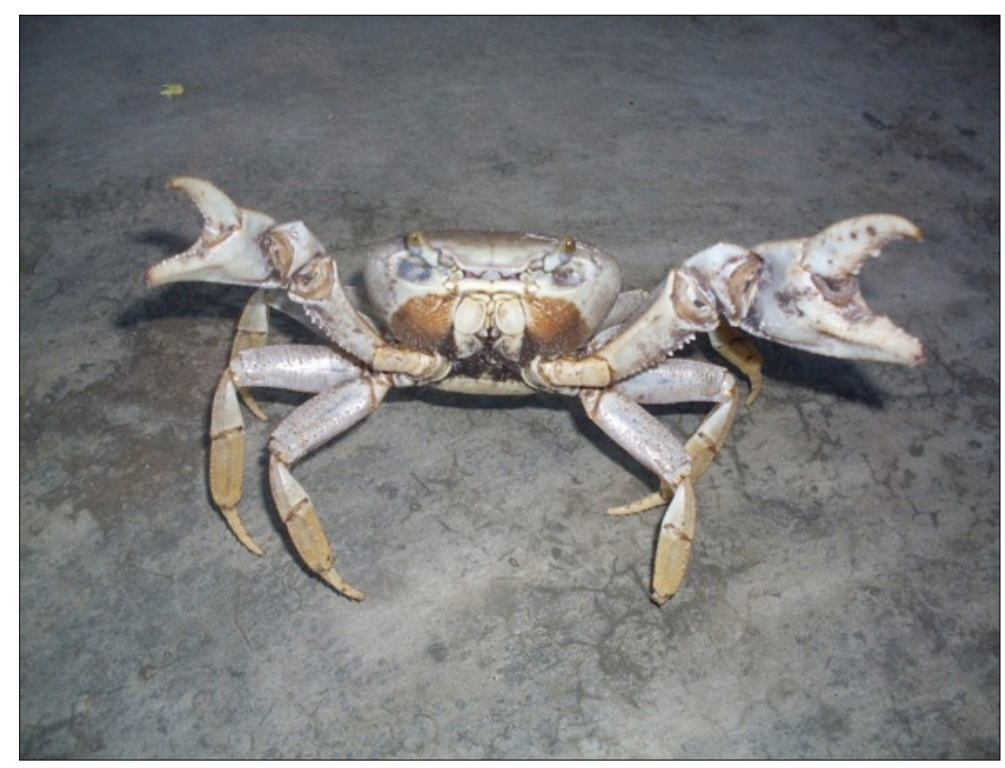

Figura 4: Fêmea do gaiamum (Cardisoma guanhumi) ovígera, denominada localmente de "choca". Foto: Henrique F. de Magalhães

$\mathrm{Na}$ etnotaxonomia do gaiamum, critérios morfológicos relacionados à coloração do animal (caranguejo-azul) e ecológicos (caranguejo-da-terra, caranguejo-de-brejo, caranguejo-do-mato) são também utilizados. Evidencia-se, ainda, os nomes choca e pata-choca (Figura 4), referentes à fêmea ovígera. Nessa fase de sua vida, esse animal adquire um padrão de coloração diferenciado, ficando amarelado, deixando temporariamente a coloração azul-arroxeada característica da espécie (PINHEIRO e FISCARELLI, 2001; CASTILLO, 2006). Essa mudança de padrão morfológico também é percebida pelos pescadores artesanais locais.

Costa-Neto e Gordiano-Lima (2000), em estudo etnobiológico desenvolvido nas comunidades pesqueiras de Poças e Siribinha (Conde-BA), observaram que o gaiamum é conhecido pelos pescadores e marisqueiras com três nomes distintos: gaiamum-pata-choca (fêmea ovada), gaiamum-dedo-roxo e gaiamum-azulão, devido à coloração azul-arroxeada das pernas e "casco". Curiosamente, os dois últimos etnonomes não foram registrados na presente pesquisa. O específico gaiamum-panã, embora inserido no táxon genérico politípico gaiamum, refere-se à espécie Armases angustipes Dana, 1852(Grapsidae).

Ferreira et al. (2007), no trabalho desenvolvido junto aos catadores e pescadores da comunidade de Tramataia, localizada às margens do estuário do Rio Mamanguape, evidenciaram a coloração como critério morfológico para identificar e nomear os específicos goiamumcaboclo e goiamum-azulão, sendo o primeiro de coloração azul-escura e amarela e o segundo, de coloração azul-clara, sendo por isso considerado de outro "tipo". No mesmo estudo, a denominação de goiamum-patigual foi registrada para alguns desses animais que apresentam as duas pernas (quelípodos) de tamanhos iguais, e as fêmeas ovadas são denominadas localmente de branca-farinha, devido à coloração adquirida por elas durante a fase reprodutiva, critério este que vale tanto para o goiamum-caboclo como para o goiamum-azulão. 
Tabela 2: Análise etnossemântica de alguns dos nomes comuns dos principais crustáceos braquiúros de importância econômica em Conde, litoral norte do Estado da Bahia, Brasil

\begin{tabular}{clc}
\hline Padrão de nomenclatura & Nomes comuns & Características nominativas \\
\hline Binomial & Caranguejo-azul & Coloração \\
& Caranguejo-gaiamum & (padrão morfológico) \\
& Siri-nema & \\
& Siri-sara & \\
& Caranguejo-da-lama & \\
& Caranguejo-da-terra & \\
& Caranguejo-de-brejo & \\
& Caranguejo-do-mato & Hábitat \\
& Siri-de-pedra & (padrão ecológico) \\
& Siri-do-mangue & \\
& Siri-do-rio & \\
& Siri-ponta-coroa & \\
& Caranguejo-uçá & \\
& Caranguejo-uçáu & \\
& Uçau & \\
& Gaiamum & \\
\hline
\end{tabular}

\section{CONCLUSÕES}

Os pescadores artesanais do município de Conde, Litoral Norte baiano, possuem conhecimentos acerca da etnotaxonomia de crustáceos braquiúros de importância econômica na região, os quais são compatíveis com os Princípios de Classificação Etnobiológica propostos por Berlin (1992). Não obstante, o conhecimento registrado pode ser comparado com o conhecimento de outras comunidades pesqueiras ao longo do litoral nordestino para identificar a ocorrência de padrões na etnotaxonomia de crustáceos braquiúros.

Com base nos resultados obtidos, percebe-se que os nomes comuns registrados refletem um conhecimento e percepção acerca da biologia e ecologia dos animais. Este saber pode ser considerado em futuros estudos visando manejo, conservação e uso sustentável desses recursos pesqueiros na região.

\section{REFERÊNCIAS}

ALVES, M. S. et al. Zooartesanato comercializado em Recife, Pernambuco, Brasil. Revista Brasileira de Zoociências, Juiz de Fora, v. 8, n. 2, p. 99-109, 2006.

ALVES, A. G. C.; SOUZA, R. M. Etnoecologia de um ambiente estuarino no Nordeste do Brasil: conhecimento dos "mariscos" por mulheres no Canal de Santa Cruz. In: MANGROVE 2000. CONFERÊNCIA SOBRE USO SUSTENTÁVEL DE ESTUÁRIOS E MANGUEZAIS: DESAFIOS E PERSPECTIVAS, 2000, Recife. Anais...Recife: UFRPE; ISME, 2000. (CD-ROM).

BERLIN, B. Ethnobiological classification: principles of categorization of plants and animals in traditional societies. Princeton University Press, Princeton, USA, 1992. $335 \mathrm{p}$.

BLANDIN, P.; LAMOTTE, M. Recherche d'une entité écologique correspondant à l'étude des paysages: la notion d'écocomplexe. Bulletin d'écologie, Paris, v. 19, n. 4, p. 547-555, 1988.

CASCUDO, L. C. Dicionário do folclore brasileiro. Rio de Janeiro: Ediouro, 1972. 1054 p. 
CENTRO DE ESTATÍSTICA E INFORMAÇÕES. Informações básicas dos municípios baianos:região litoral norte.Salvador: Governo do Estado da Bahia, 1994. 320 p.

CASTILHO, G. G. Aspectos reprodutivos do caranguejo-uçá, Ucides cordatus (L.) (Crustacea, Brachyura, Ocypodidae), na Baía de Antonina, Paraná, Brasil. Dissertação (Mestrado em Ciências Veterinárias), Universidade Federal do Paraná, Curitiba, 2006.

COSTA-NETO, E. M. Restrições e preferências alimentares em comunidades de pescadores do município de Conde, Estado da Bahia, Brasil. Revista de Nutrição, Campinas, v. 13, n. 2, p. 117-126, 2000.

COSTA-NETO, E. M. A cultura pesqueira do litoral norte da Bahia: etnoictiologia, desenvolvimento e sustentabilidade. Salvador: EDUFBA; Maceió: EDUFAL, 2001. $121 \mathrm{p}$.

COSTA-NETO, E. M.; GORDIANO-LIMA, K. L. 2000. Contribuição ao estudo da interação entre pescadores e caranguejos (Crustacea, Decapoda, Brachyura): considerações etnobiológicas em uma comunidade pesqueira do Estado da Bahia, Brasil. Actualidades Biológicas, Bogotá, v.22, n. 73, p. 195-202, 2000.

COUTO, H. H. Ecolingüística. Estudo das relações entre língua e meio ambiente. Brasília: Thesaurus Editora, 2007.

FERREIRA, E. N. et al. Taxonomia folk dos catadores de siris (Crustacea-Portunidae) do Estuário do Rio Mamanguape-Paraíba-Brasil. In: ENCONTRO DE ZOOLOGIA DO NORDESTE, 16, 2007, Garanhuns. Anais...Vol. 8 - Etnozoologia. Garanhuns: UFRPE, 2007.

GOODMAN, L. A. Amostragem bola de neve. Annals of Mathematical Statistics, Bethesda, v. 32, p. 148170, 1961.

GREENE, E. S. Ethnocategories, social intercouse, fear and redemption. Comment on Laurent. Society and Animals, v. 3, n. 1 (online), 1995. Disponível em: http://www.psyeta.org/sa/sa3.1/greene.html. Acesso em 04 fev 2009.

GUEST, M. A. et al. Mechanism for the small-scale movement of carbon among estuarine habitats: Organic matter transfer not crab movement. Oecologia, Londres, v. 148, p. 88-96, 2006.

HARRIS, M. History and significance of the emic/ etic distinction. Annual Review of Anthropology, New York,v. 5, p. 329-350, 1976.

HYNOBRAN, D. C. Hunting and the classification of game animals among the wapkaimin. Oceania, Sydney, v. 54, n. 4), p. 289-309, 1984.

JANKOWSKY, M.; PIRES, J. S. R.; NORDI, N. Contribuição ao manejo participativo do caranguejo-uçá, Ucides cordatus (L., 1763), em Cananéia, SP. Boletim do Instituto de Pesca, São Paulo, v. 32, n. 2, p. 221228, 2006.

LAGES-FILHO, J. A medicina popular emAlagoas. Salvador: Instituto Nina Rodrigues, 1934. 68 p.

MAGALHÃES, H. F.; COSTA NETO, E. M.; SCHIAVETTI, A.Local knowledge of traditional fishermen on economically important crabs (Decapoda: Brachyura) in the city of Conde, Bahia State, Northeastern Brazil.Journal of Ethnobiology and Ethnomedicine 2012, v. 8:13. Disponível em: http://www.ethnobiomed.com/content/8/1/13. Acesso em 12 abr 2013.

MAGALHÃES, J. Medicina folclórica. Fortaleza: Imprensa Universitária do Ceará, 1966. 98 p.

MOURÃO, J. S.; NORDI, N. Principais critérios utilizados por pescadores artesanais na taxonomia folk dos peixes do estuário do rio Mamanguape, Paraíba - Brasil. Interciencia, Caracas, v. 27, n. 11, p. 607-612, 2002.

NASCIMENTO, D. M. et al. Impactos sócio-ambientais provocados pela técnica "redinha" na captura do caranguejo-uçá Ucides cordatus no estuário do Rio Mamanguape (PB). In: ENCONTRO DE BIOLOGIA DA UEFS, 9; ENCONTRO NORDESTINO DE ETNOECOLOGIA E ETNOBIOLOGIA, 4., 2008, Feira de Santana. Resumos... Feira de Santana: UEFS, 2008.

NOMURA, H. Os crustáceos na cultura popular. Mossoró: Fundação Vingt-Un Rosado, 2001. 62 p.

PINHEIRO, M. A. A.; FISCARELLI, A. G. Manual de apoio à fiscalização do caranguejo-uçá (Ucides cordatus). Jaboticabal: UNESP/CEPSUL/IBAMA, 2001.

POSEY, D. A. Etnobiologia: teoria e prática. In: RIBEIRO, D. (ed.).Suma Etnológica Brasileira. Etnobiologia. Petrópolis: Vozes, 1986. p. 15-25.

REITERMAJER, D. Comunidade extrativista do manguezal de Porto Sauípe, Entre Rios-BA: uma abordagem ecológica e social. 1996. Monografia. UFBA, Salvador, 1996. 
ROUÉ, M. Novas perspectivas em etnoecologia: "saberes tradicionais" e gestão dos recursos naturais. In: CASTRO, E.; PINTON, E. (orgs.). Faces do trópico úmido: conceitos e novas questões sobre desenvolvimento e meio ambiente. Belém: Cejup-UFPA-NAEA, 1997. p. 187-200.

RUPPERT, E. E.; FOX, S.; BARNES, R. D. Zoologia dos invertebrados: uma abordagem funcional-evolutiva. 7a ed. São Paulo: Editora Roca, 2005. 1.145 p.

SCHAEFFER-NOVELLI, Y. Manguezal: ecossistema entre a terra e o mar. São Paulo: Caribbean Ecological Research, 1995. 64 p.

SILVA, A F. et al. Zooartesanato comercializado na costa da Paraíba (Nordeste do Brasil): implicações ecológicas e conservacionistas. In: CONGRESSO DE ECOLOGIA DO BRASIL, 8., 2007, Caxambu, Minas Gerais. Anais... Disponível em: http://www.seb-ecologia.org.br/viiiceb/pdf/1082.pdf

SILVA, F. P. M. Aspectos etnozoológicos sobre os crustáceos estomatópodes e decápodes das praias do litoral norte da Bahia, Brasil. 2014. 92 f. Dissertação (Mestrado em Zoologia), Universidade Estadual de Feira de Santana, Feira de Santana, 2014.

SILVA, I. G.; NISHIDA, A. K. Etnoclassificação dos siris praticada pelos pescadores da região estuarina do Rio Vaza-Barris, Sergipe, Brasil. In: SIMPÓSIO BRASILEIRO DE ETNOBIOLOGIA E ETNOECOLOGIA, 8., 2008, Belém. Resumos... Belém: UFPA, 2008

SOUTO, F. J. B. A ciência que veio da lama.Uma abordagem etnoecológica abrangente das relações ser humano/ manguezal na comunidade pesqueira de Acupe, Santo Amaro-BA. 2004. 319 f. Tese (Doutorado em Ecologia e Recursos Naturais), Universidade Federal de São Carlos, São Carlos, 2004.

SOUTO, F. J. B.; MARQUES, J. G. W. "O siri labuta muito!" Uma abordagem etnoecológica abrangente da pesca de um conjunto de crustáceos no manguezal de Acupe, Santo Amaro, Bahia, Brasil. SitientibusSérie Ciências Biológicas, Feira de Santana, v. 6, especial Etnobiologia, p. 106-119, 2006.

SOUZA, G. S. Tratado descritivo do Brasil em 1587: edição castigada pelo estudo e exame de muitos códices manuscritos existentes no Brasil, em Portugal, Espanha e França e acrescentada de alguns comentários por Francisco Adolfo de Varnhagen.9. ed. rev. atual. Recife: FJN; Ed. Massagana, 2000.

SPRADLEY, J. P.; MCCURDY, D. W. The cultural experience: ethnography in complex society. Tennessee: Kingsport Press of Kingsport, 1972. 200 p.

STURTEVANT, W. C. Studies in ethnoscience. American Anthropologist, New York, v. 66, n. 3, p. 99-131, 1964.

TURBAY, S. Aproximaciones a los estudios antropológicos sobre la relación entre el ser humano y los animales. In:ULLOA, A. (Ed.). Rostros culturales de la fauna: las relaciones entre los humanos y los animales en el contexto colombiano. Bogotá: Instituto Colombiano de Antropología e Historia/ Fundación Natura, 2002. p. 87-111.

WERNER, O. The basic assumptions of ethnoscience. Semiotica, Londres, v. 1, p. 329-338, 1969. 